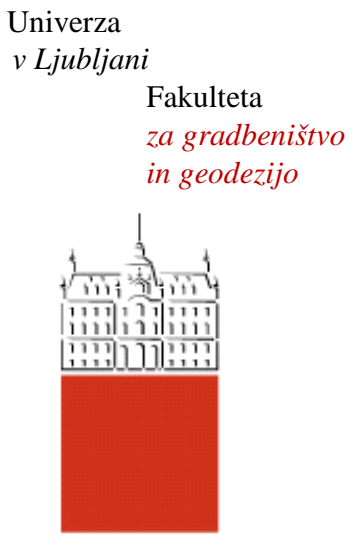

Jamova cesta 2

1000 Ljubljana, Slovenija

http://www3.fgg.uni-lj.si/

DRUGG - Digitalni repozitorij UL FGG http://drugg.fgg.uni-lj.si/

Ta članek je avtorjeva zadnja recenzirana različica, kot je bila sprejeta po opravljeni recenziji.

Prosimo, da se pri navajanju sklicujte na bibliografske podatke, kot je navedeno:
University
of Ljubljana

Faculty of

Civil and Geodetic

Engineering

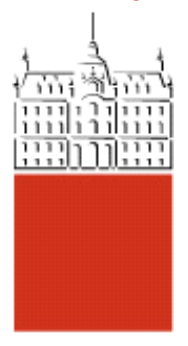

Jamova cesta 2

SI - 1000 Ljubljana, Slovenia

http://www3.fgg.uni-lj.si/en/

DRUGG - The Digital Repository http://drugg.fgg.uni-lj.si/

This version of the article is author's manuscript as accepted for publishing after the review process.

When citing, please refer to the publisher's bibliographic information as follows:

Žvanut, P., Turk, G., Kryžanowski, A. 2015. Effects of changing surrounding conditions on the thermal analysis of the Moste concrete dam. Journal of performance of constructed facilities, 1-9.

DOI: 10.1061/(ASCE)CF.1943-5509.0000776. 


\title{
Effects of Changing Surrounding Conditions on the Thermal Analysis of the Moste Concrete Dam
}

\author{
Pavel Žvanut ${ }^{1}$, Goran Turk $^{2}$ and Andrej Kryžanowski ${ }^{3}$
}

${ }^{1}$ Researcher, ZAG - Slovenian National Building and Civil Engineering Institute, Dimičeva 12, 1000 Ljubljana, Slovenia (corresponding author). E-mail: pavel.zvanut@zag.si.

${ }^{2}$ Professor, Faculty of Civil and Geodetic Engineering, University of Ljubljana, Jamova 2, 1000 Ljubljana, Slovenia. E-mail: goran.turk@fgg.uni-lj.si.

${ }^{3}$ Assistant Professor, Faculty of Civil and Geodetic Engineering, University of Ljubljana, Jamova 2, 1000 Ljubljana, Slovenia. E-mail: andrej.kryzanowski@fgg.uni-lj.si.

\begin{abstract}
This paper deals with the heat transfer analysis of the 63 years old and 60 metres high Moste concrete arch-gravity dam, located in NW Slovenia. The analysis was performed after a new sophisticated monitoring system had been established, making it possible to perform continuous measurements of the temperatures of the concrete, of the water, and of the surroundings of the dam, i.e. the air temperatures and the amount of solar insolation. An equation defining nonlinear and non-stationary heat conduction in the case of a two-dimensional space, for a homogeneous isotropic solid whose thermal conductivity is independent of temperature, was solved numerically by means of the finite element method, taking into account appropriate boundary conditions. The latter involved the effects of changing conditions of the surroundings (i.e. shading, convection, and solar radiation) during the analysed period of 15 consecutive clear days in the summer. The results show that the measured and calculated temperatures of the concrete at different locations, and at different depths, were in very good agreement.
\end{abstract}

ASCE Subject Headings: Concrete Dams, Thermal Analysis, Heat Transfer, Finite Element Method, Measuring Instruments, Monitoring, Time Series Analysis, Solar Radiation, Convection, Temperature Effects.

\section{Introduction}

Thermal analyses of various engineering structures, including concrete structures, are now very widespread. A few decades ago, some basic research in the field of thermal analyses, taking into account nonlinear and non-stationary heat conduction through solids, and subject to appropriate boundary conditions, was performed (Dilger et al. 1983, Carslaw and Jaeger 1986). Using this type of analysis it was possible to obtain better solutions to the problems involved in the impact of temperature loading on concrete dam structures (Bernstone 2006; ICOLD 2000, 2012; U.S. Army Corps of Engineers 1994, 1995). A methodology based on thermal analysis that used the finite element method (FEM) to identify critical temperature conditions during the course of the year, and for the calculation of stresses in concrete gravity dams, was presented by Leger et al. (1993a), who, in a separate paper, described the results of extensive parametric analyses that were performed in order to determine the thermal behaviour of concrete gravity dams of different heights (Leger et al. 1993b). A large number of papers on this interesting topic can be found in 
the literature (Agullo et al. 1996; Ardito et al. 2008; Ishikawa 1991; Leger et al. 1995; Malkawi et al. 2003; Noorzaei et al. 2006; Saetta et al. 1995; Wu and Luna 2001; Yang et al. 2012; Zhang et al. 1997).

A considerable amount of research has been conducted on the calculation of thermal fields in the case of the conduction of heat in massive concrete structures, and a number of papers on this subject have recently been published (Ganelli et al. 2012; Hu et al. 2013; Jin et al. 2010; Labibzadeh et al. 2010; Leger and Leclerc 2007; Leger and Seydou 2009; Maken et al. 2014; Malm and Ansell 2011; Obernhuber and Perner 2005; Xu et al. 2012; Weber et al. 2010). All of these papers have analyzed the behaviour of concrete dam structures, taking into account approximate assumptions regarding environmental effects on dams.

Some researchers took into account, with slightly more accuracy, the effects of changing surrounding conditions (Sheibany and Ghaemian 2006). The difference was that, compared to similar previous studies, they also took into account the changes which occurred due to the share of solar radiation on the exposed surface of the dam, as well as the actual water temperature in the reservoir. However, it seems that no detailed measurement data are available in the literature about the changes which occur, in the years after such dams have been built, in temperature fields inside the dam due to seasonal and daily temperature changes.

In this paper the authors present a relatively simple numerical model for the calculation of nonlinear and non-stationary heat conduction, which, importantly, can take into account the variable boundary conditions on the upstream side of the dam due to changes in the water level of the reservoir, as well as the impact of shading on the downstream, insolated side of the dam. The accuracy of the proposed model was verified on the basis of the results of field measurements performed at the Moste dam, located in NW Slovenia, using new equipment for the automatic measurement of temperatures (i.e. of the air, the water, and the concrete) making it possible to obtain detailed data about the changing concrete temperatures at different depths inside the dam.

\section{Heat Transfer Analysis}

\section{Equation of conduction}

The heat transfer process in the case of a concrete dam is presented in Fig. 1.

In the case of a homogeneous isotropic solid whose thermal conductivity is independent of temperature, and a three-dimensional (3-D) space, the equation which defines the conduction of heat for changing surrounding conditions (Carslaw and Jaeger 1986) is:

$$
\frac{\partial^{2} T}{\partial x^{2}}+\frac{\partial^{2} T}{\partial y^{2}}+\frac{\partial^{2} T}{\partial z^{2}}=\frac{\rho \cdot c}{\lambda} \cdot \frac{\partial T}{\partial t}
$$

where $T$ is the temperature $(\mathrm{K}) ; x, y, z$ are the Cartesian coordinates $(\mathrm{m}) ; \rho$ is the density $\left(\mathrm{kg} / \mathrm{m}^{3}\right)$; $c$ is the specific heat capacity $(\mathrm{J} /(\mathrm{kg} \cdot \mathrm{K})) ; \lambda$ is the thermal conductivity $(\mathrm{W} /(\mathrm{m} \cdot \mathrm{K}))$; and $t$ is time (s). 
A special form of the Eq. (1), which is valid for two-dimensional (2-D) space, can be defined as follows:

$$
\frac{\partial^{2} T}{\partial x^{2}}+\frac{\partial^{2} T}{\partial y^{2}}=\frac{\rho \cdot c}{\lambda} \cdot \frac{\partial T}{\partial t}
$$

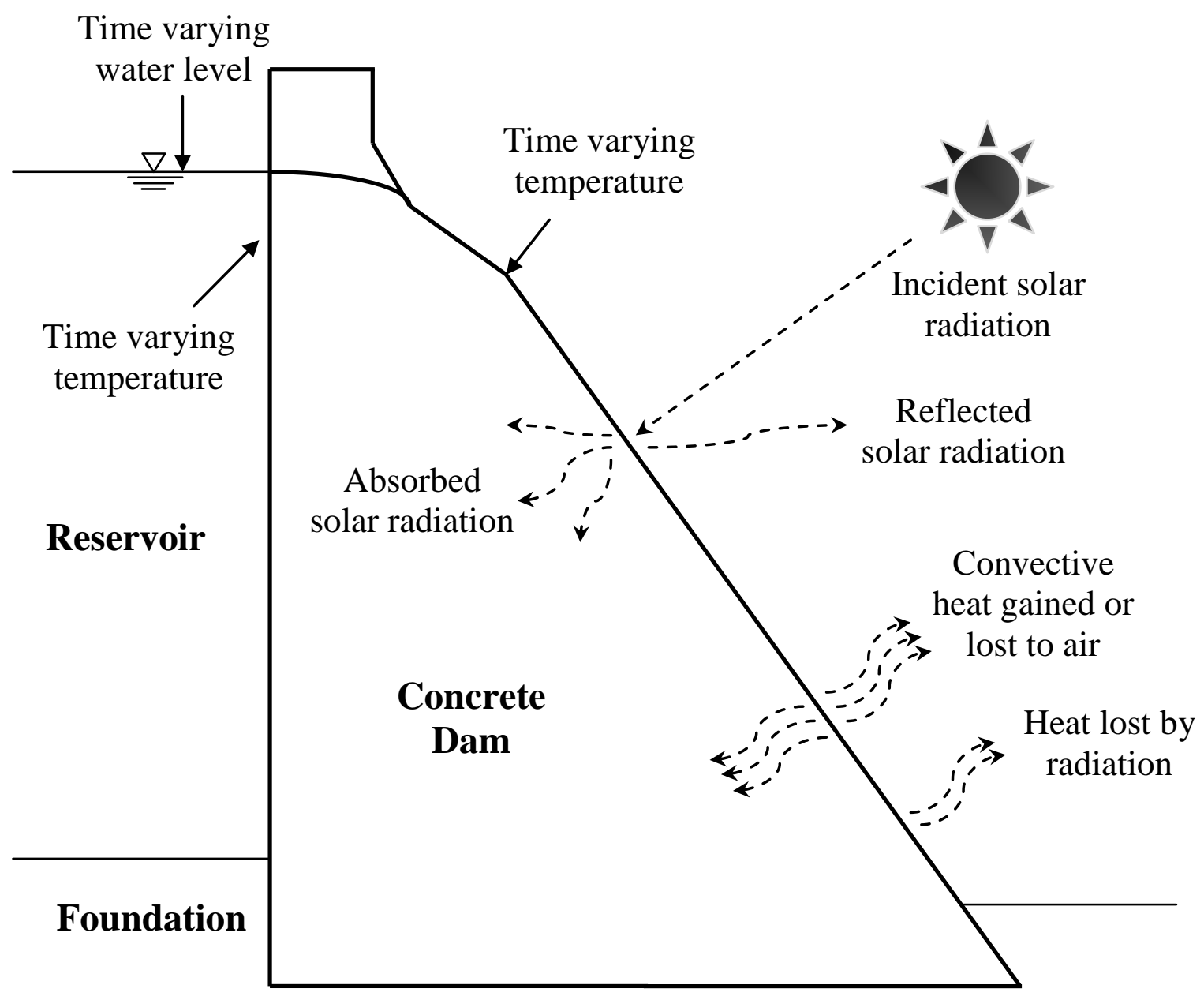

Fig. 1. Heat transfer process for a concrete dam

\section{Boundary conditions}

Eq. (2) has to be solved under appropriate boundary conditions. The basic types of these conditions are:

1. Prescribed temperature on the surface (e.g. constant, or time-dependent),

2. Prescribed heat flow on the surface (e.g. absorption of the solar radiation taking into account the effect of shading (i.e. solar exposure or non-exposure of the observation point)), 
3. Heat flow is linearly dependent on the temperature difference between the surface and the ambient temperature (e.g. in the case of convection on heat transfer onto the surface),

4. Heat flow is non-linearly dependent on the temperature difference between the surface and the ambient temperature (e.g. radiation from the surface of the solid).

The exchange of heat by convection as a result of temperature differences between the exposed surface and the ambient temperature is given by the equation:

$$
q_{c}=h_{c} \cdot\left(T-T_{a}\right)
$$

where $q_{c}$ is the convective flux $\left(\mathrm{W} / \mathrm{m}^{2}\right) ; h_{c}$ is the convection coefficient $\left(\mathrm{W} /\left(\mathrm{m}^{2} \cdot \mathrm{K}\right)\right)$; $T$ is the temperature of the dam surface in contact with the air $(\mathrm{K})$; and $T_{a}$ is the ambient temperature $(\mathrm{K})$.

Heat transfer by convection is a complex phenomenon, and can be influenced by many variables in its numerical implementation (shape and rugosity of the surface, viscosity, the speed of the fluid, etc.). Some formulae have been proposed for the definition of the convection heat transfer coefficient, which can be used to determine accurately the amount of heat transferred by convection. These formulas are (Duffie and Beckman 2006):

$$
\begin{array}{ll}
h_{c}=5.7+3.8 \cdot V & \text { (McAdam) } \\
h_{c}=2.8+3.0 \cdot V & \text { (Watmuff) }
\end{array}
$$

where $V$ is the fluid speed (wind speed) $(\mathrm{m} / \mathrm{s})$.

Exchange of heat by electromagnetic radiation is measured by the Stefan-Boltzman law:

$$
q_{r}=e \cdot C_{s} \cdot\left(T^{4}-T_{a}^{4}\right)
$$

where $q_{r}$ is the radiation flux $\left(\mathrm{W} / \mathrm{m}^{2}\right)$; $e$ is the emissivity of the surface; and $C_{s}$ is the StefanBoltzman constant $\left[5.669 \times 10^{-8}\left(\mathrm{~W} / \mathrm{m}^{2}\right)\right]$.

Eq. (5) can be re-written in a linear form as follows:

$$
q_{r}=h_{r} \cdot\left(T-T_{a}\right)
$$

where $h_{r}$ is a linearized radiation coefficient $\left(\mathrm{W} / \mathrm{m}^{2}\right)$, and is defined by the expression:

$$
h_{r}=e \cdot C_{s} \cdot\left(T^{2}+T_{a}^{2}\right) \cdot\left(T+T_{a}\right)
$$

In the text which follows a relatively simple procedure proposed by Dilger et al. (1983) for the fairly accurate determination of energy flux density due to the absorption of solar radiation is described.

The amount of solar energy absorbed by the body of a system is given by: 


$$
q_{s}=I \cdot a \cdot \cos \theta
$$

where $q_{s}$ is the energy flux density of solar radiation absorbed by the solid $\left(\mathrm{W} / \mathrm{m}^{2}\right)$; $I$ is the energy flux density of solar radiation at the earth's surface $\left(\mathrm{W} / \mathrm{m}^{2}\right)$; $a$ is the solar absorptivity of the surface; and $\theta$ is the angle of incidence of the sun's rays $\left(^{\circ}\right)$.

$$
I=I_{s c} \cdot k_{T}
$$

where $I_{s c}$ is the solar constant [on average $1,350 \mathrm{~W} / \mathrm{m}^{2}$ ]; and $k_{T}$ is the transparency factor, which depends on the weather conditions in the atmosphere and from the path length of the radiation through the atmosphere.

$$
k_{T} \cong 0.9^{\left(k_{A} \cdot m \cdot t_{U}\right)}
$$

where $k_{A}$ is factor of altitude $H$, where $H$ is measured in metres; $m$ is the factor of influence of the relative path length of the radiation (depending on the solar elevation angle $\beta_{s}$ ); and $t_{U}$ is an air pollution factor (between 1.8 for clean air and 9.0 for very polluted air).

$$
\begin{aligned}
& k_{A} \cong 1-0.000105 \cdot H \\
& m \cong \frac{1}{\sin \beta_{s}}, \quad \text { if } \beta_{s} \geq 5^{\circ} \\
& m \cong \frac{1}{\sin 5^{\circ}}, \quad \text { if } \beta_{s}<5^{\circ}
\end{aligned}
$$

The angle of incidence of the sun's rays can be presented by:

$$
\begin{aligned}
& \cos \theta=-\cos \delta \cdot \cos \Omega \cdot \sin \alpha \cdot \cos \tau \cdot \sin \Phi+\cos \delta \cdot \sin \Omega \cdot \sin \alpha \cdot \sin \tau+\sin \delta \cdot \cos \Omega \cdot \sin \alpha \cdot \cos \Phi+ \\
& +\cos \delta \cdot \cos \alpha \cdot \cos \tau \cdot \cos \Phi+\sin \delta \cdot \cos \alpha \cdot \sin \Phi \\
& \text { and } \quad \cos \theta \geq 0
\end{aligned}
$$

where $\delta$ is the declination (i.e. the angle between the equatorial plane and the direction of the sun), positive towards the North Celestial Pole; $\Omega$ is the azimuth of the normal to the plane measured clockwise from north; $\alpha$ is the angle between the plane and the Earth's surface; $\Phi$ is the geographical latitude; and $\tau$ is the hour angle (positive in the morning) which is denoted by:

$$
\tau=(12-u) \cdot 15^{\circ}
$$

where $u$ is the time of day in 24-hour notation (the hour angle changes at a rate of $15^{\circ}$ per hour). In the case of the vertical plane $\left(\alpha=90^{\circ}\right) \mathrm{Eq}$. (13) can be simplified into:

$$
\cos \theta=-\cos \delta \cdot \cos \Omega \cdot \cos \tau \cdot \sin \Phi+\cos \delta \cdot \sin \Omega \cdot \sin \tau+\sin \delta \cdot \cos \Omega \cdot \cos \Phi
$$


Whereas in the case of the horizontal plane $\left(\alpha=0^{\circ}\right)$ it can be simplified into:

$$
\cos \theta=\cos \delta \cdot \cos \tau \cdot \cos \Phi+\sin \delta \cdot \sin \Phi=\sin \beta_{s}
$$

where $\beta_{s}$ is the solar elevation angle.

The solar azimuth angle $\left(\alpha_{s}\right)$ defines in which direction the sun is, assuming the north-clockwise convention, and it can be defined by the expression:

$$
\begin{gathered}
\cos \alpha_{s}=\frac{\sin \delta-\sin \beta_{s} \cdot \sin \Phi}{\cos \beta_{s} \cdot \cos \Phi} \\
\text { If } \tau>0(u<12 \text {, in the morning }) \rightarrow \alpha_{s}<180^{\circ} \\
\text { If } \tau<0(u>12 \text {, in the afternoon }) \rightarrow \alpha_{s}>180^{\circ}
\end{gathered}
$$

The amount of solar radiation reaching the concrete surface (which is a tilted surface) follows cyclical seasonal variations. In the case of concrete arch-gravity dams, various parts of the exposed surface have different slopes and orientations. Consequently, the total solar radiation which reaches these areas has spatial variations across the whole exposed surface of a dam.

\section{Numerical solution}

Taking into account the appropriate boundary conditions Eq. (2) can also be solved numerically using, for example, the FEM (see e.g. Zienkiewicz 1977). Finite element discretization results in a system of nonlinear differential equations of the first order, which can be used in the case of the searched time-dependent node temperatures. The matrix form of the system of differential equations is:

$$
\mathbf{K} \cdot \mathbf{T}+\mathbf{C} \cdot \mathbf{T}, t=\mathbf{F}
$$

where $\mathbf{K}$ is the thermal conductivity matrix; $\mathbf{T}$ is the nodal temperature vector; $\mathbf{C}$ is the heat capacity matrix; $\mathbf{T}, t$ is the time derivative of temperature; and $\mathbf{F}$ is the vector of the external actions.

The coefficients and the right hand side of Eq. (18) depend, in general, on the desired temperatures (T), whereas the right hand side is also usually an explicit function of time $(t)$.

$$
\mathbf{K}(\mathbf{T}) \cdot \mathbf{T}+\mathbf{C}(\mathbf{T}) \cdot \mathbf{T}, t=\mathbf{F}(\mathbf{T}, t)
$$

\section{The Moste Dam}

\section{General Data}

The main characteristics of the Moste dam are presented in Table 1. The thermal properties of the mass concrete used in the analysis are given in Table 2. 


\section{Preliminary Analysis and Establishment of the Measuring System}

\section{Concrete Temperatures}

Before determining the locations of the temperature gauges on the concrete, preliminary calculations and analyses of the results of the conduction of heat through the massive concrete structure were performed using the HeatC computer program, developed at the Faculty of Civil and Geodetic Engineering of the University of Ljubljana, where four-node planar isoparametric finite elements were used for the engineering computational model (Ilc et al. 2009). In these analyses, the latest available meteorological data obtained from the nearby weather station, which was located about $6 \mathrm{~km}$ away from the dam, were used. Also, calculations with different thicknesses of the massive concrete structure and different boundary conditions were taken into account. According to the results of these analyses, which were performed in 2013, i.e. 61 years after the construction of the Moste dam, the temperature monitoring system was established. Five concrete temperature gauges were installed near the downstream surface of the dam in two boreholes, which were located at the most appropriate locations inside the dam (i.e. the minimum length of the boreholes in the central cross-section of the dam, leading from the vertical shaft or the inspection gallery to, and in the direction perpendicular to, the downstream surface of the concrete dam).

Table 1. Main Characteristics of the Moste Dam

\begin{tabular}{lcc}
\hline Characteristic & Unit & Value \\
\hline Type & $/$ & Concrete Arch Gravity \\
Year of Completion & $/$ & 1952 \\
Structural Height & $\mathrm{m}$ & 59.80 \\
Crest Length & $\mathrm{m}$ & 72.00 \\
Dam Volume & $\mathrm{m}^{3}$ & 42,000 \\
Crest Altitude (Steel Gates) & $\mathrm{m}$ a.s.l. & 524.75 \\
Crest Altitude (Concrete) & $\mathrm{m}$ a.s.l. & 523.50 \\
Operational Water Level & $\mathrm{m}$ a.s.l. & $518.00-524.75$ \\
Reservoir Capacity & $\mathrm{m}^{3}$ & $6,240,000$ \\
Reservoir Surface Area & $\mathrm{m}^{2}$ & 620,000 \\
Reservoir Length & $\mathrm{km}^{2}$ & 5 \\
Catchment Area & $\mathrm{km}^{2}$ & 325 \\
Geographical Latitude (North) & $\circ$ & 46.41 \\
Azimuth (Downstream Side) & $\mathrm{o}$ & 186 \\
\hline
\end{tabular}

${ }^{\mathrm{a}}$ Clockwise from North 
Table 2. Thermal Properties of the Mass Concrete

\begin{tabular}{lcc}
\hline Material Property & Unit & Value \\
\hline Density & $\mathrm{kg} / \mathrm{m}^{3}$ & 2,400 \\
Specific Heat Capacity & $\mathrm{J} /(\mathrm{kg} \cdot \mathrm{K})$ & 960 \\
Thermal Conductivity & $\mathrm{W} /(\mathrm{m} \cdot \mathrm{K})$ & 2.33 \\
Convection Coefficient (Air) & $\mathrm{W} /\left(\mathrm{m}^{2} \cdot \mathrm{K}\right)$ & 55.6 \\
Convection Coefficient (Water) & $\mathrm{W} /\left(\mathrm{m}^{2} \cdot \mathrm{K}\right)$ & 556 \\
Solar Absorptivity & $/$ & 0.65 \\
Emissivity & $/$ & 0.90 \\
\hline
\end{tabular}

The upper borehole, which was $2.22 \mathrm{~m}$ long, was drilled from the top of the vertical shaft, whereas the lower one, which was $3.53 \mathrm{~m}$ long, was drilled from the lower inspection gallery. In the upper borehole, four gauges were installed at the following distances from the downstream concrete dam surface: $10 \mathrm{~cm}, 20 \mathrm{~cm}, 50 \mathrm{~cm}$ and $100 \mathrm{~cm}$, whereas in the lower borehole one gauge was installed at a distance of $10 \mathrm{~cm}$ from the downstream concrete dam surface. The concrete temperature gauges were installed in the special protection tubes, which also facilitated their installation, and the whole volume between the individual tube and the borehole was filled with material which had very similar thermal properties to those of the surrounding concrete. Both of the boreholes were sealed, at their top end, with $10 \mathrm{~cm}$ thick cylindrical core caps. One additional gauge for the concrete temperature measurements was installed in the borehole on the upstream side of the dam, $30 \mathrm{~cm}$ from the concrete-water interface, at an elevation of $521.2 \mathrm{~m}$. An overview of the locations of the concrete temperature gauges is given in Table 3 and in Fig. 2.

Table 3. Description of the locations of the concrete temperature gauges

\begin{tabular}{cccc}
\hline Gauge & $\begin{array}{c}\text { Elevation } \\
(\mathrm{m} \text { a.s.l.) }\end{array}$ & $\begin{array}{c}\text { Distance from the } \\
\text { concrete surface }(\mathrm{m})\end{array}$ & $\begin{array}{c}\text { Boundary medium } \\
\text { (Air/Water) }\end{array}$ \\
\hline TC1 & 520.3 & 0.1 & Air \\
TC2 & 520.2 & 0.2 & Air \\
TC3 & 520.0 & 0.5 & Air \\
TC4 & 519.6 & 1.0 & Air \\
TC5 & 521.2 & 0.3 & Air or Water \\
TC6 & 485.2 & 0.1 & Air \\
\hline
\end{tabular}




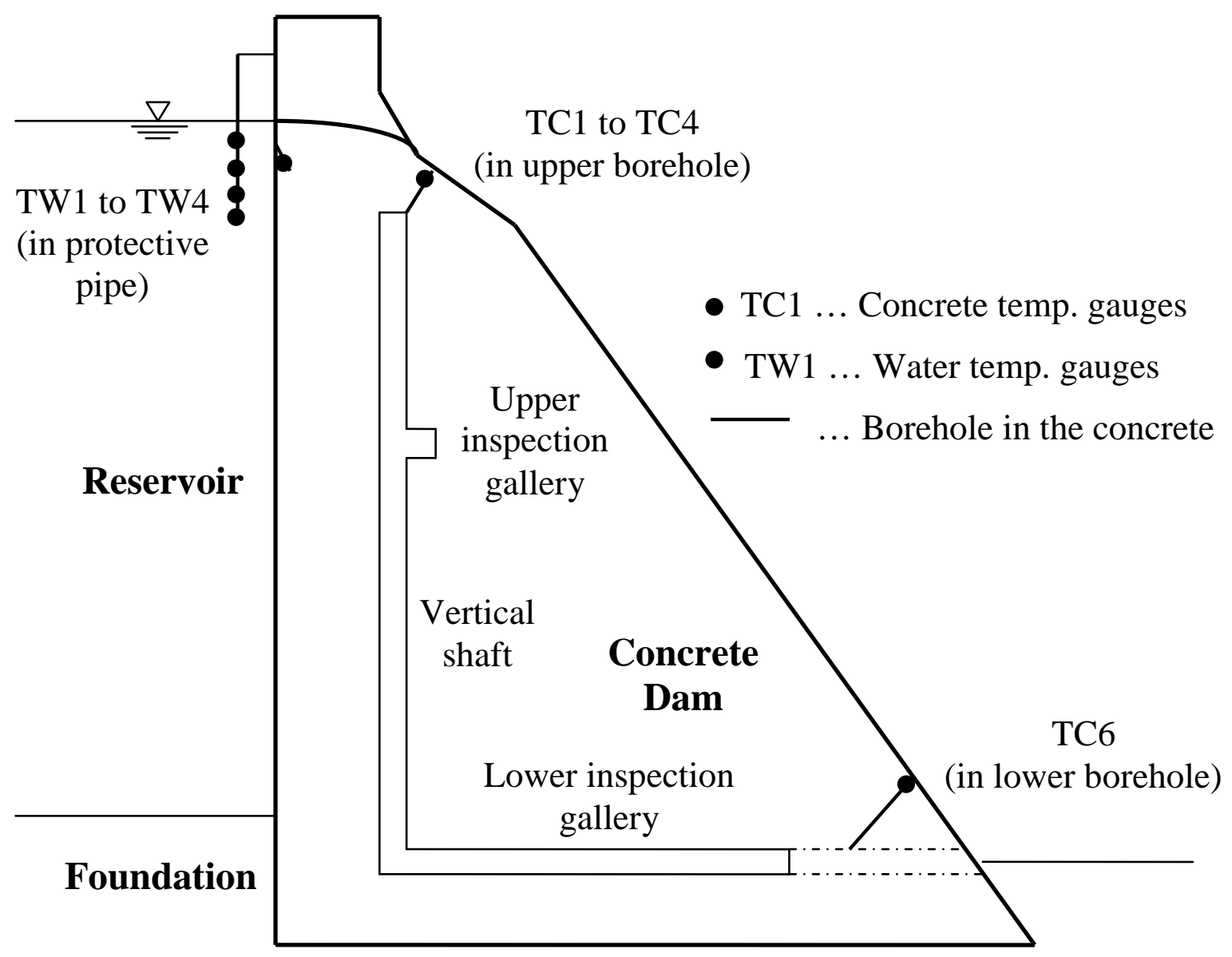

Fig. 2. Central cross-section of the Moste dam with the established monitoring system for the temperature measurements

\section{Water Temperatures}

Before determining the elevations of the water temperature gauges, preliminary analysis of available data about the changing, in the past, of the water level in the Moste reservoir was performed. Analyses were performed of the data relating to oscillations of operational water levels for the past 30 years, and it was found that the normal multiannual average level of the operational zone is located between elevations $522 \mathrm{~m}$ and $524 \mathrm{~m}$. Accordingly, four gauges for the water temperature measurements were installed in a special vertical steel pipe, which protected against rushing waters and floating debris and was located about $2 \mathrm{~m}$ away from the dam, at elevations of $519 \mathrm{~m}, 521 \mathrm{~m}, 522 \mathrm{~m}$ and $523 \mathrm{~m}$. Gauge TW1 was placed at a depth where it was not affected by the surface zone of changing water temperature. The epilimnion reaches up to $2 \mathrm{~m}$, whereas the water temperature distribution at greater depths is practically constant, and also changes very little according to the season (Toman 1997). An overview of the locations of the water temperature gauges is given in Table 4 and Fig. 2. 
After establishment of the monitoring system for the temperature measurements, the one-hour data were first collected in data loggers and then, once a month, the data were transferred by radio to the portable computer which was located at a distance of approximately 20 metres from the data logger.

Table 4. Description of the locations of the water temperature gauges

\begin{tabular}{cc}
\hline Gauge & Elevation (m a.s.l.) \\
\hline TW1 & 519.0 \\
TW2 & 521.0 \\
TW3 & 522.0 \\
TW4 & 523.0 \\
\hline
\end{tabular}

\section{Surrounding Conditions}

The surrounding conditions were measured using the mobile automatic weather station (MAWS) Vaisala, which was appropriately located in the immediate vicinity of the Moste dam (see Figure 3). It was necessary to locate the MAWS with precision in order to obtain real data about the air temperature $(\mathrm{K})$, the solar radiation $\left(\mathrm{W} / \mathrm{m}^{2}\right)$, the wind speed $(\mathrm{m} / \mathrm{s})$, the wind direction $\left(^{\circ}\right)$, and the precipitation (mm). The final location was determined after a careful visual inspection of the area of the dam, where three main parameters were considered:

1. the location should be in an open space with a minimum of topographic obstacles (to get real data of the measured parameters),

2. it should be easily accessible (for the performance of maintenance, if needed),

3. it should not be too easily visible or at a popular location (to avoid possible vandalism).

After installation of the weather station some nearby topographic obstacles (trees) were removed. Data about the surrounding conditions, registered every ten minutes, were first collected in the data logger and then, once a week, the data were transferred to the desktop computer via a GSM communication channel.

\section{Results of the Measurements and Analyses}

\section{Effect of Shading}

The effect of shading (i.e. solar exposure or non-exposure of the observation point on the dam) on the thermal analysis of the Moste dam was determined by using the following three steps (Žvanut et al. 2014):

1. In the first step, a total of seven appropriate locations for the laser scanning of the whole area of the dam were determined; three sites downstream from the dam, three sites at the crest of the dam and one site above the area of the dam. After this, measurements of the topography of the wider area of the dam were performed using terrestrial laser scanner (TLS) with a camera, which provided detailed and accurate 3D data (i.e. a cloud with about 50 million measuring points) both rapidly and efficiently. 
2. In the second step, the original cloud of the measuring points was filtered, to a distance of $0.5 \mathrm{~m}$ between the measuring points, so after that a more manageable number of measuring points (i.e. about 225,000 ) became available (a distance parameter of less than $0.5 \mathrm{~m}$ would cause negligible differences in the final result upon calculation of shading). The filtered point cloud was then imported into a Mathematica (Wolfram Research Inc. 2014) computing environment, where an elaborate computer program calculated the horizontal and vertical angles between the selected observation point on the dam and other imported points from the point cloud. The contours of the surrounding terrain and of the dam itself were determined, for the chosen observation point on the dam, by calculating the greatest elevation angles at different azimuths (i.e. clockwise from the north direction; from $80^{\circ}$ to $280^{\circ}$, with a horizontal angle and step of $5^{\circ}$ ). The azimuths were determined in the horizontal plane, using the unit vector $\mathbf{A}=\{0,1\}$ showing the north direction, and the projection of the vector $\mathbf{B}$ on the horizontal plane $\mathbf{B}_{\mathbf{H}}=\left\{y_{1}-y_{0}, x_{1}-x_{0}\right\}$ showing any other direction, where $+\mathrm{x}$ is the north direction and $+y$ is the east direction (see Fig. 4). The elevation angles were then calculated in 3-D space, using the vector $\mathbf{B}_{\mathbf{H}}=\left\{y_{1}-y_{0}, x_{1}-x_{0}, 0\right\}$ in the horizontal plane and vector $\mathbf{B}=\left\{y_{1}-y_{0}, x_{1}-x_{0}, H_{1}-H_{0}\right\}$ at $H_{1}>H_{0}$, where $\mathrm{T}_{0}=\left\{y_{0}, x_{0}, H_{0}\right\}$ are the coordinates of the chosen observation point on the dam; $\mathrm{T}_{1}=\left\{y_{1}, x_{1}, H_{1}\right\}$ are the coordinates of the point on the surrounding terrain or on the dam, at the chosen azimuth, for the calculation of elevation angle; and $+H$ is the zenith direction.

3. In the last step, the contours of the surrounding terrain and the dam itself were compared with the position of the sun during the year (i.e. the greatest elevation angles at different azimuths were, for various observation points, compared with the elevation angles of the sun, depending on the day of the year and time of the day) and the solar exposure or nonexposure of the observation point on the dam was finally calculated (see Fig. 5). 


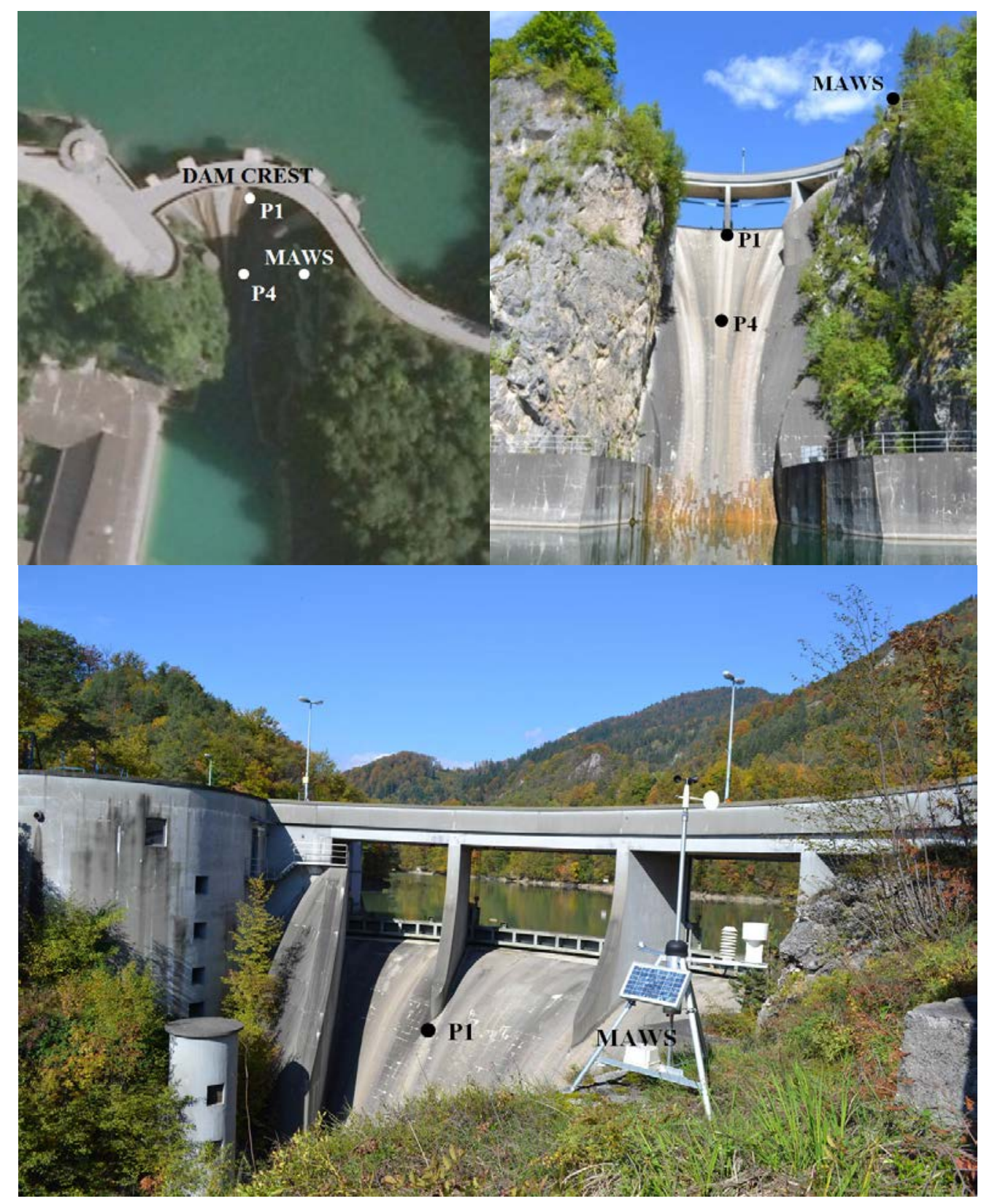

Fig. 3. Location of the MAWS, close to the dam 


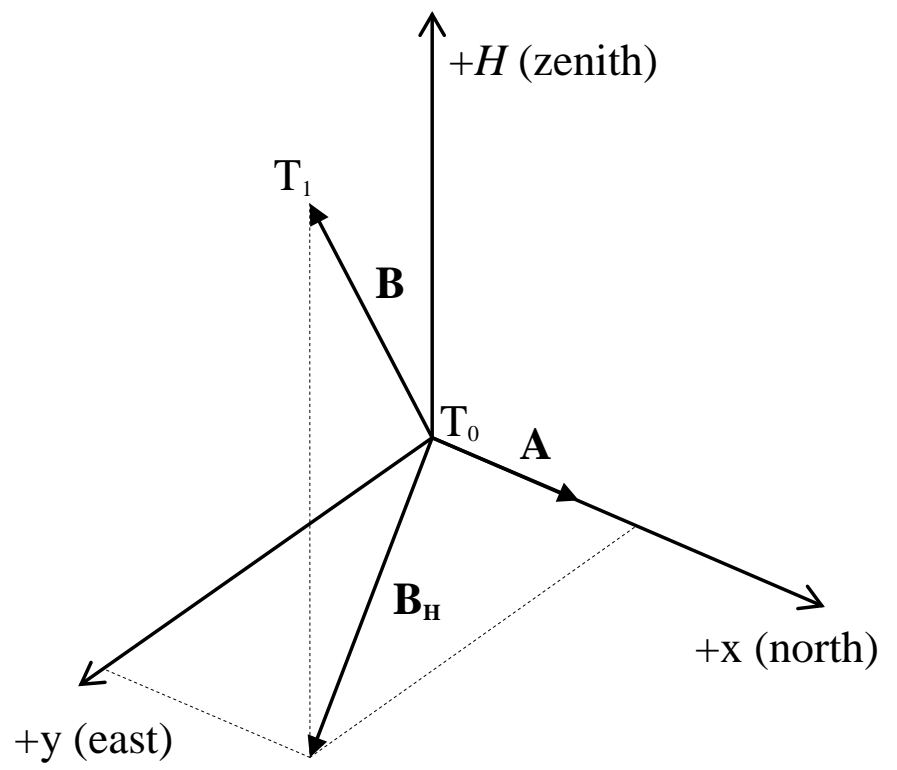

Fig. 4. Position of vectors in coordinate system

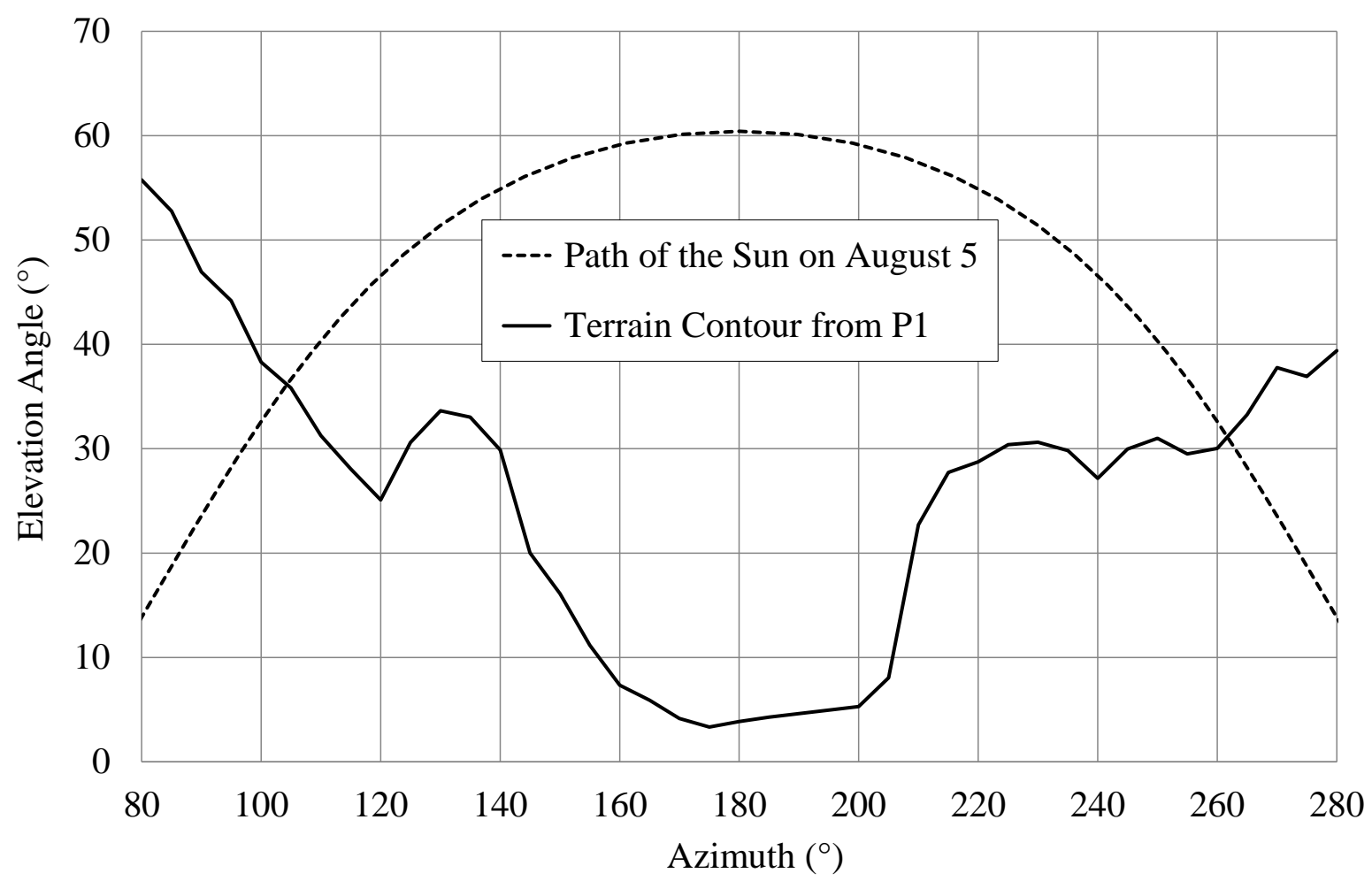

Fig. 5. Contour of the surrounding terrain as seen from the observation point P1 and virtual path of the sun on August 5 


\section{Solar Radiation}

First, back-analyses of the solar radiation were performed by using the HeatC computer program in the MatLab (MathWorks 2014) computing environment, at the location of MAWS, and calibrated parameters were obtained. The analysed period covered 15 consecutive clear days, between July 25 and August 8. The results for the first seven days of the analysed period show that the measured and back-calculated values were in very good agreement (see Fig. 6). The results for the last eight days of the analysed period show that the differences were, at this time, almost negligible.

Figure 7 shows the calculated solar radiation on the clear day of August 5, at three observation points located at different locations, i.e. at different shading conditions, and at differently oriented planes (see Fig. 3 and Tab. 5), and measured solar radiation at one observation point (MAWS). At the location of MAWS the measured and the calculated values of solar radiation were in very good agreement. The initial part of the curve indicating the measured values represents the diffused radiation, i.e. radiation before the start of direct insolation.

Table 5. Location of the observation points at differently oriented planes

\begin{tabular}{cccc}
\hline $\begin{array}{c}\text { Observation Point } \\
\text { on the Plane }\end{array}$ & $\begin{array}{c}\text { Altitude } \\
(\mathrm{m})\end{array}$ & $\begin{array}{c}\text { Angle to the } \\
\text { Horizontal Plane }\left(^{\circ}\right)\end{array}$ & $\begin{array}{c}\text { Azimuth } \\
\left({ }^{\circ}\right)\end{array}$ \\
\hline MAWS & 527.65 & 0 & $/$ \\
Point P1 & 520.35 & 30 & 186 \\
Point P4 & 485.30 & 43 & 186 \\
\hline
\end{tabular}

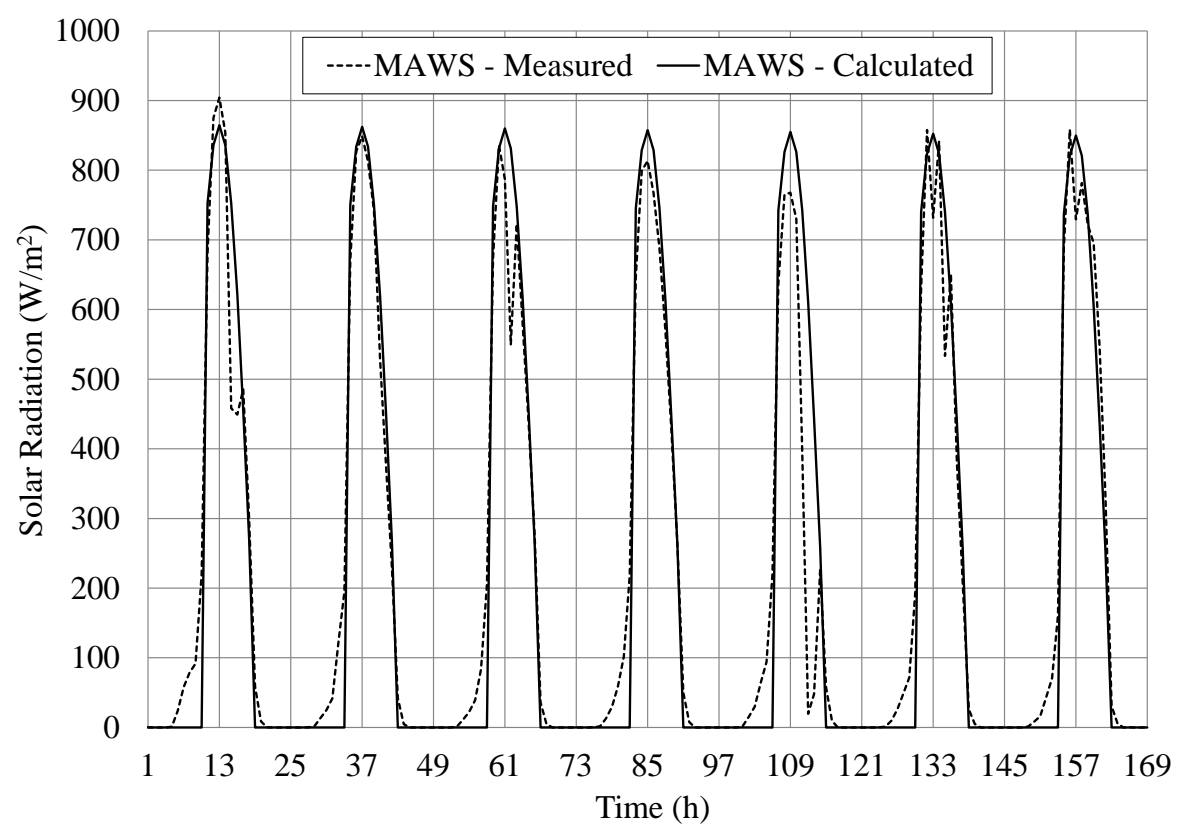

Fig. 6. Solar radiation during the first seven days of the discussed period 


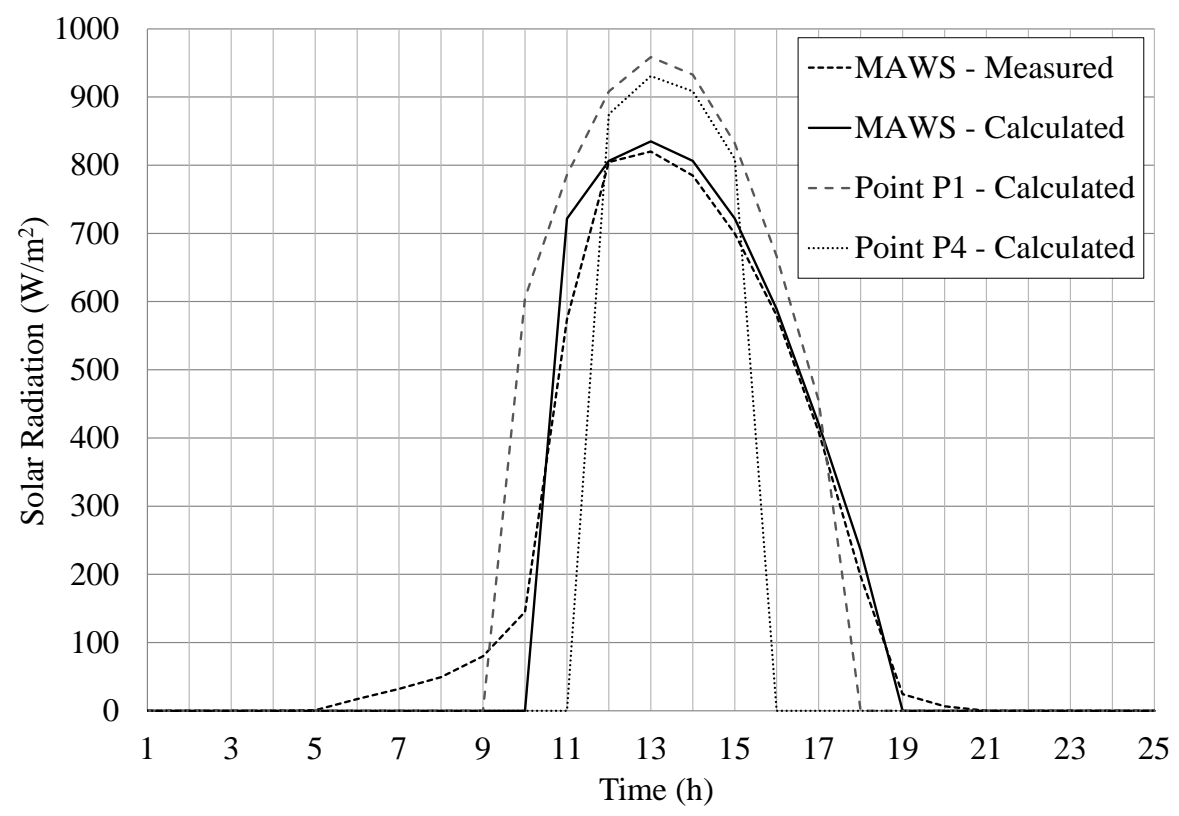

Fig. 7. Solar radiation on the clear day of August 5, at three observation points located at different locations and at different oriented planes

\section{Heat Transfer Analyses}

Heat transfer analyses were then performed, using the HeatC computer program in the MatLab computing environment, for the instrumented locations in the Moste dam, taking into account the previous results of the effect of shading and solar radiation. The initial temperature of the concrete was obtained in such a way that during the preliminary analyses the temperature after five days was first calculated and then five repetitions of this period were made, each time using temperature at the end of the period as starting value of the next repetition. The initial temperature at the first repetition was set to $20^{\circ} \mathrm{C}$. However, this arbitrary choice did not have significant importance. To nullify the influence of the selected initial temperature, the initial value at the actual calculation was taken from the end of the fifth repetition. Figures 8 to 11 show the measured and calculated concrete temperatures at gauges TC1 to TC4, which were located in the upper borehole, at distances of $0.1 \mathrm{~m}, 0.2 \mathrm{~m}, 0.5 \mathrm{~m}$ and $1.0 \mathrm{~m}$ from the downstream concrete surface, and the measured air temperatures at the location of MAWS, during the analysed period of 15 consecutive clear days.

Table 6 shows the concrete temperature oscillations (daily, and for the analysed period) and the time lags at gauges TC1 to TC4, which were located in the upper downstream borehole, as well as the air temperature oscillations. 
Table 6. Temperature oscillations and time lags at gauges TC1 to TC4

\begin{tabular}{|c|c|c|c|c|c|c|c|c|c|c|}
\hline \multirow{3}{*}{$\begin{array}{l}\text { Oscill./ } \\
\text { Lag }\end{array}$} & \multirow[b]{3}{*}{ Limit } & \multicolumn{9}{|c|}{ Temperature $\left({ }^{\circ} \mathrm{C}\right)$} \\
\hline & & \multirow{2}{*}{$\begin{array}{l}\text { Air } \\
M\end{array}$} & \multicolumn{2}{|c|}{ TC1 } & \multicolumn{2}{|c|}{ TC2 } & \multicolumn{2}{|c|}{ TC3 } & \multicolumn{2}{|c|}{ TC4 } \\
\hline & & & $\mathrm{M}$ & $\mathrm{C}$ & $\mathrm{M}$ & $\mathrm{C}$ & $\mathrm{M}$ & $\mathrm{C}$ & $\mathrm{M}$ & $\mathrm{C}$ \\
\hline \multirow{3}{*}{$\begin{array}{l}\text { Daily }^{\mathrm{a}} \\
\text { Oscill. }\end{array}$} & $\mathrm{T} \min$ & 18.2 & 23.2 & 23.4 & 24.3 & 25.6 & 24.9 & 27.2 & 23.3 & 25.7 \\
\hline & $\mathrm{T} \max$ & 38.8 & 35.1 & 35.6 & 31.1 & 32.1 & 25.9 & 28.1 & 23.4 & 26.1 \\
\hline & Diff. & 20.7 & 11.9 & 12.3 & 6.8 & 6.6 & 1.0 & 0.9 & 0.1 & 0.3 \\
\hline \multirow{3}{*}{$\begin{array}{l}\text { Period } \\
\text { Oscill. }\end{array}$} & $\mathrm{T} \min$ & 13.7 & 22.5 & 19.5 & 23.2 & 22.0 & 23.7 & 25.0 & 22.1 & 25.0 \\
\hline & $\mathrm{T} \max$ & 40.1 & 37.6 & 35.7 & 33.5 & 32.2 & 27.5 & 28.2 & 23.8 & 26.1 \\
\hline & Diff. & 26.4 & 15.1 & 16.2 & 10.3 & 10.2 & 3.8 & 3.2 & 1.7 & 1.1 \\
\hline Time & $\mathrm{T}$ min & & \multirow{2}{*}{\multicolumn{2}{|c|}{$3-4^{\mathrm{b}}$}} & \multirow{2}{*}{\multicolumn{2}{|c|}{$\begin{array}{l}4-5^{\mathrm{b}} \\
2-3^{\mathrm{b}}\end{array}$}} & \multirow{2}{*}{\multicolumn{2}{|c|}{$\begin{array}{l}10-12^{\mathrm{b}} \\
10-12^{\mathrm{b}}\end{array}$}} & \multirow{2}{*}{\multicolumn{2}{|c|}{$\begin{array}{l}\text { several days } \\
\text { several days }\end{array}$}} \\
\hline Lag & $\mathrm{T} \max$ & & & & & & & & & \\
\hline
\end{tabular}

Note: $\mathrm{M}=$ measured; $\mathrm{C}=$ calculated.

${ }^{\mathrm{a}}$ Day 14 of the analysed period.

${ }^{\mathrm{b}}$ Time Lag in hours/several days.

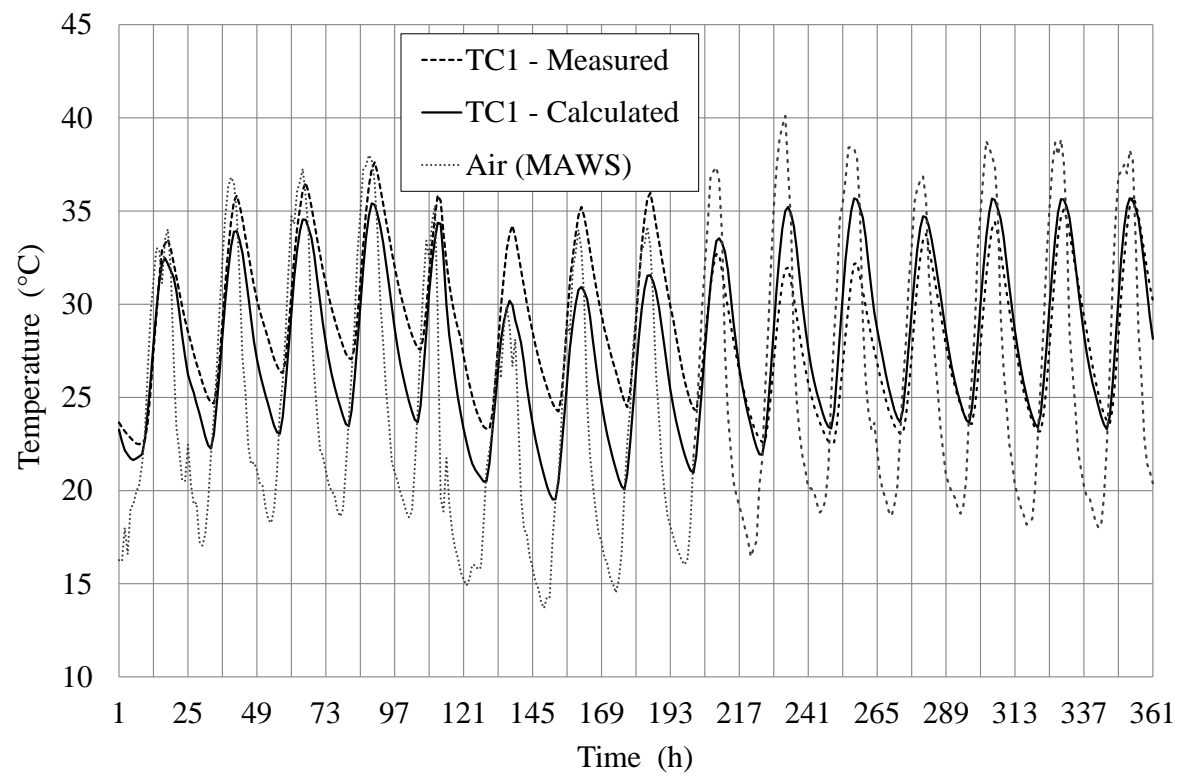

Fig. 8. Concrete temperatures at the gauge TC1 during the discussed period 


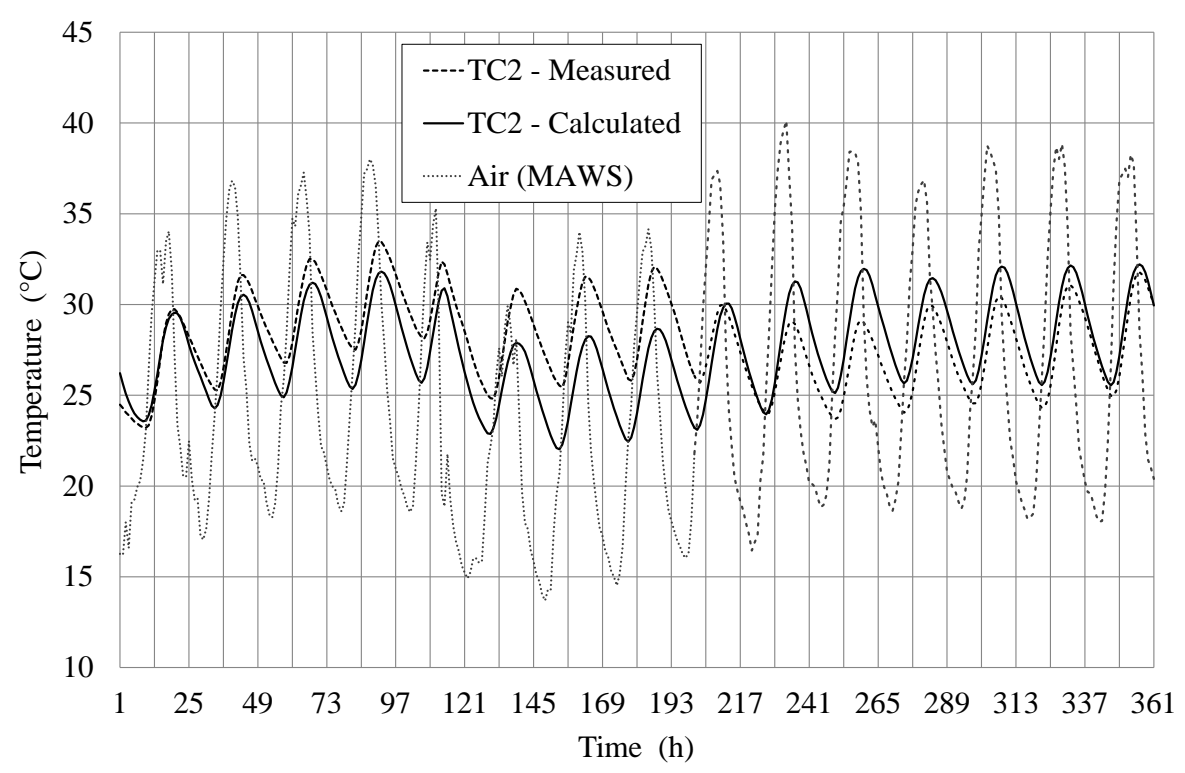

Fig. 9. Concrete temperatures at the gauge TC2 during the discussed period

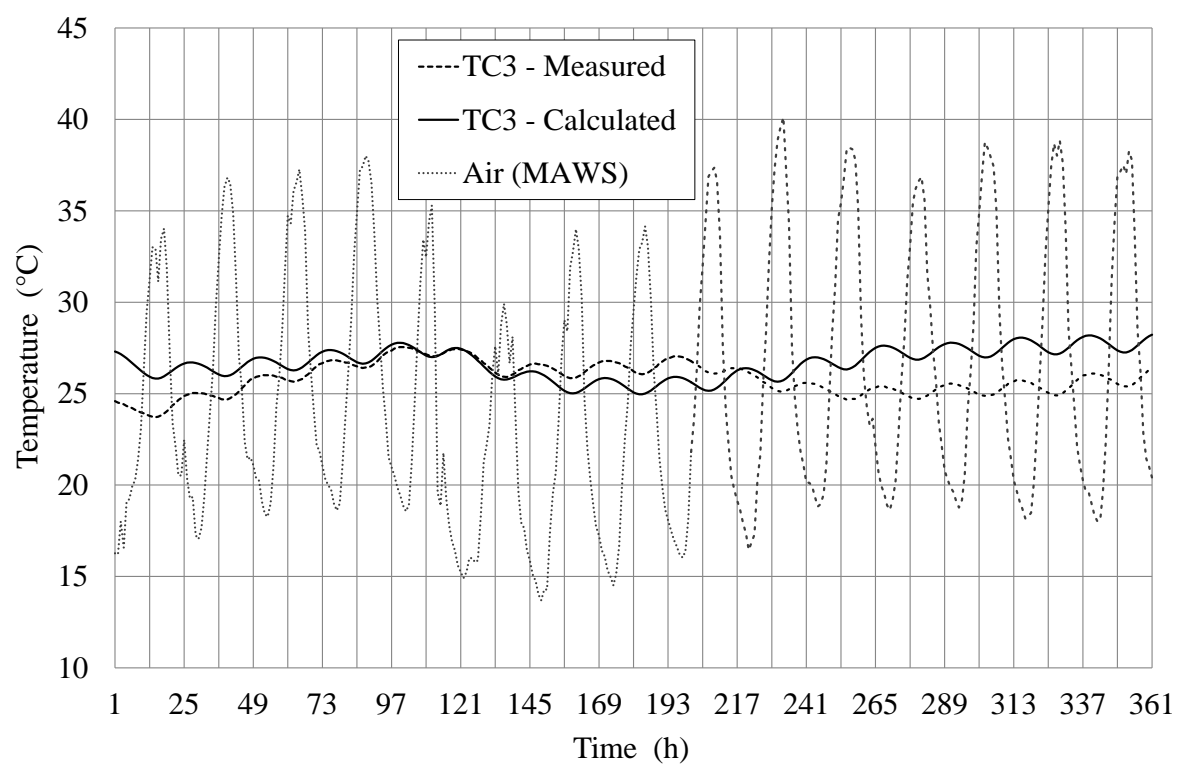

Fig. 10. Concrete temperatures at the gauge TC3 during the discussed period

The daily oscillations of the air temperatures for the chosen day amounted to between 18.2 and $38.8^{\circ} \mathrm{C}$, so their amplitude is $20.7^{\circ} \mathrm{C}$. At gauge TC1, located $0.1 \mathrm{~m}$ from the surface, the measured daily oscillations were up to $11.9^{\circ} \mathrm{C}$, and the calculated daily oscillations up to 12.3 ${ }^{\circ} \mathrm{C}$, whereas at gauge $\mathrm{TC} 2$, located $0.2 \mathrm{~m}$ from the surface, the daily oscillations were significantly smaller (6.8 and $6.6^{\circ} \mathrm{C}$, respectively). At the location of gauge TC3, i.e. $0.5 \mathrm{~m}$ from 
the surface, the daily oscillations were around $1{ }^{\circ} \mathrm{C}$, whereas half a metre deeper from the surface, at gauge TC4, the measured daily oscillations were only $0.1{ }^{\circ} \mathrm{C}$, and the calculated oscillations $0.3^{\circ} \mathrm{C}$.

The oscillations of the air temperatures, over the analysed period, were between 13.7 and 40.1 ${ }^{\circ} \mathrm{C}$, so their amplitude was $26.4^{\circ} \mathrm{C}$. At gauge TC1, the analysed oscillations over the same period were significantly smaller (measured $15.1^{\circ} \mathrm{C}$ and calculated $16.2^{\circ} \mathrm{C}$ ), whereas at gauge TC2 the oscillations were 10.3 and $10.2^{\circ} \mathrm{C}$, respectively. At gauge TC3 the measured period oscillations were still $3.8^{\circ} \mathrm{C}$, and the calculated oscillations up to $3.2^{\circ} \mathrm{C}$. At gauge TC4 the measured oscillations, over the analysed period, were $1.7^{\circ} \mathrm{C}$, and the corresponding calculated oscillations $1.1^{\circ} \mathrm{C}$.

At gauge TC1 the time lag at the minimum temperatures amounted to 3 to 4 hours, whereas the time lag at the maximum temperatures was 1 to 2 hours (see Figure 8). At gauge TC2 the time lag was slightly longer (at minimum temperatures 4 to 5 days, and at maximum temperatures 2 to 3 days). At a depth of half a metre, at gauge TC3, the time lag amounted to already 10 to 12 hours, whereas at a depth of one metre, at gauge TC4, the time lag amounted to several days.

The measured and calculated concrete temperatures at gauge TC5, which was located in the upstream borehole, at a distance of $0.3 \mathrm{~m}$ from the upstream concrete surface, are shown in Figure 12, together with the measured air and water temperatures (depending on the water level) at the location of gauge TW2, and the water level in the reservoir, during the analysed period of 15 consecutive clear days.

Table 7 shows the concrete temperature oscillations (daily, and over the analysed period) and the time lags at gauge TC5, which was located in the upstream borehole, and the air temperature and water tempera ture oscillations at gauges TW2 and TW1, respectively.

Table 7. Temperature oscillations and time lags at the gauge TC5

\begin{tabular}{|c|c|c|c|c|c|c|}
\hline \multirow{3}{*}{$\begin{array}{l}\text { Oscill./ } \\
\text { Lag }\end{array}$} & \multirow[b]{3}{*}{ Limit } & \multicolumn{5}{|c|}{ Temperature $\left({ }^{\circ} \mathrm{C}\right)$} \\
\hline & & \multirow{2}{*}{$\begin{array}{l}\text { Air }^{\mathrm{a}} \\
\mathrm{M} \\
\end{array}$} & \multirow{2}{*}{$\begin{array}{l}\text { Water }^{\mathrm{a}} \\
\mathrm{M}\end{array}$} & \multirow{2}{*}{$\frac{\text { Water }^{\mathrm{b}}}{\mathrm{M}}$} & \multicolumn{2}{|l|}{ TC5 } \\
\hline & & & & & $\mathrm{M}$ & $\mathrm{C}$ \\
\hline \multirow{3}{*}{$\begin{array}{l}\text { Daily } \\
\text { Oscill. }\end{array}$} & $\mathrm{T} \min$ & / & 14.7 & 14.1 & 15.9 & 16.1 \\
\hline & $\mathrm{T} \max$ & / & 16.8 & 14.7 & 16.1 & 16.4 \\
\hline & Diff. & I & 2.1 & 0.6 & 0.2 & 0.3 \\
\hline \multirow{3}{*}{$\begin{array}{l}\text { Period } \\
\text { Oscill. }\end{array}$} & $\mathrm{T} \min$ & 16.3 & 13.8 & 13.5 & 15.8 & 16.0 \\
\hline & $\mathrm{T} \max$ & 32.5 & 19.4 & 17.9 & 18.7 & 20.6 \\
\hline & Diff. & 16.2 & 5.6 & 4.4 & 2.9 & 4.6 \\
\hline Time & \multicolumn{4}{|l|}{$\mathrm{T} \min$} & \multicolumn{2}{|c|}{$6-8^{d}$} \\
\hline Lag & \multicolumn{4}{|l|}{$\mathrm{T} \max$} & \multicolumn{2}{|c|}{$5-6^{\mathrm{d}}$} \\
\hline
\end{tabular}

Note: $\mathrm{M}=$ measured; $\mathrm{C}=$ calculated.

${ }^{a}$ At the gauge TW2.

${ }^{\mathrm{b}}$ At the gauge TW1.

${ }^{\mathrm{C}}$ Day 14 of the analysed period.

${ }^{\mathrm{d}}$ Time Lag in hours. 
The daily oscillations of the water temperature at gauge TW2 were, for the selected day, between 14.7 and $16.8{ }^{\circ} \mathrm{C}$, so that their amplitude amounted to $2.1{ }^{\circ} \mathrm{C}$, whereas at gauge TW1 the daily oscillations were between 14.1 and $14.7^{\circ} \mathrm{C}$, so that their amplitude was $0.6^{\circ} \mathrm{C}$. At gauge TC5, located $0.3 \mathrm{~m}$ from the surface, the measured daily oscillations amounted to up to $0.2^{\circ} \mathrm{C}$, and the calculated daily oscillations were up to $0.3^{\circ} \mathrm{C}$.

At gauge TW2 the oscillations of the air temperature over the analysed period were between 16.3 and $32.5^{\circ} \mathrm{C}$, so their amplitude was $16.2^{\circ} \mathrm{C}$, whereas those of the water temperatures were from 13.8 to $19.4{ }^{\circ} \mathrm{C}$, and their amplitude $5.6^{\circ} \mathrm{C}$. In the case of gauge TW1 the oscillations of the water temperatures, over the analysed period, were between 13.5 and $17.9^{\circ} \mathrm{C}$, and their amplitude was $4.4^{\circ} \mathrm{C}$. At gauge TC5 the measured oscillations, over the analysed period, were $2.9^{\circ} \mathrm{C}$, and the corresponding calculated oscillations amounted to $4.6^{\circ} \mathrm{C}$.

At gauge TC5 the time lag at the minimum temperatures was 6 to 8 hours, whereas the time lag at the maximum temperatures was 5 to 6 hours.

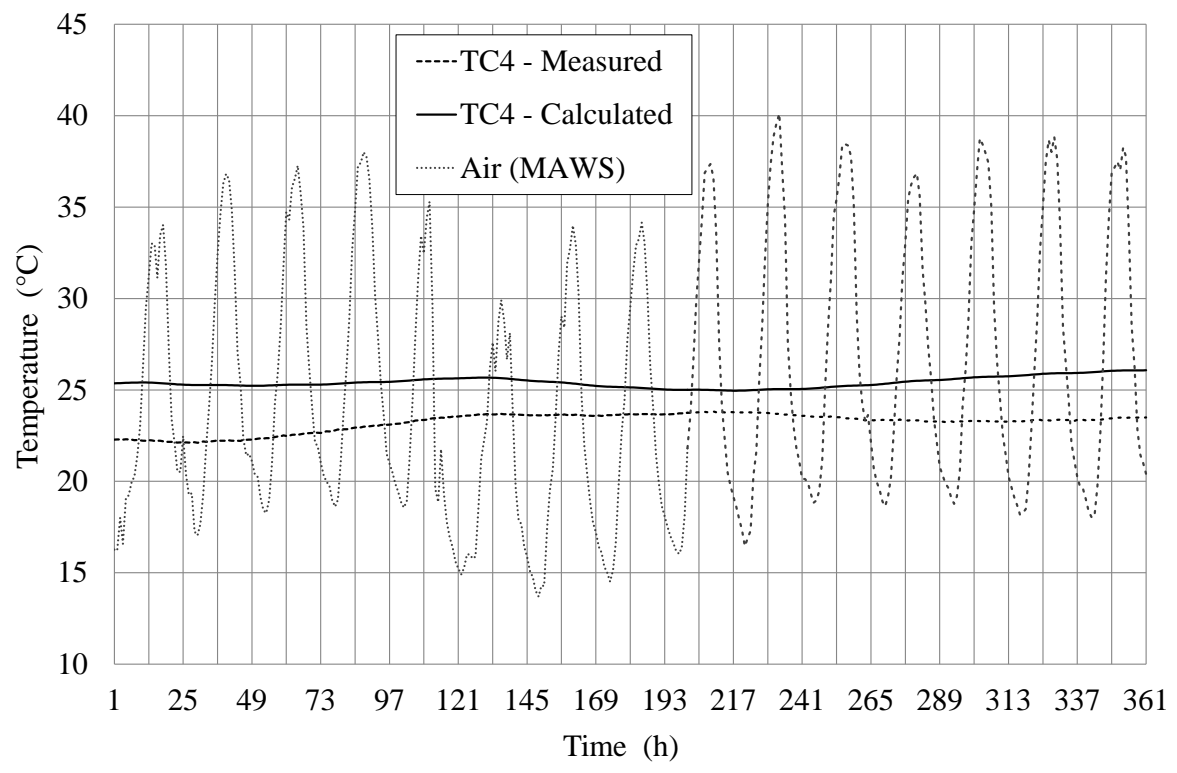

Fig. 11. Concrete temperatures at the gauge TC4 during the discussed period 


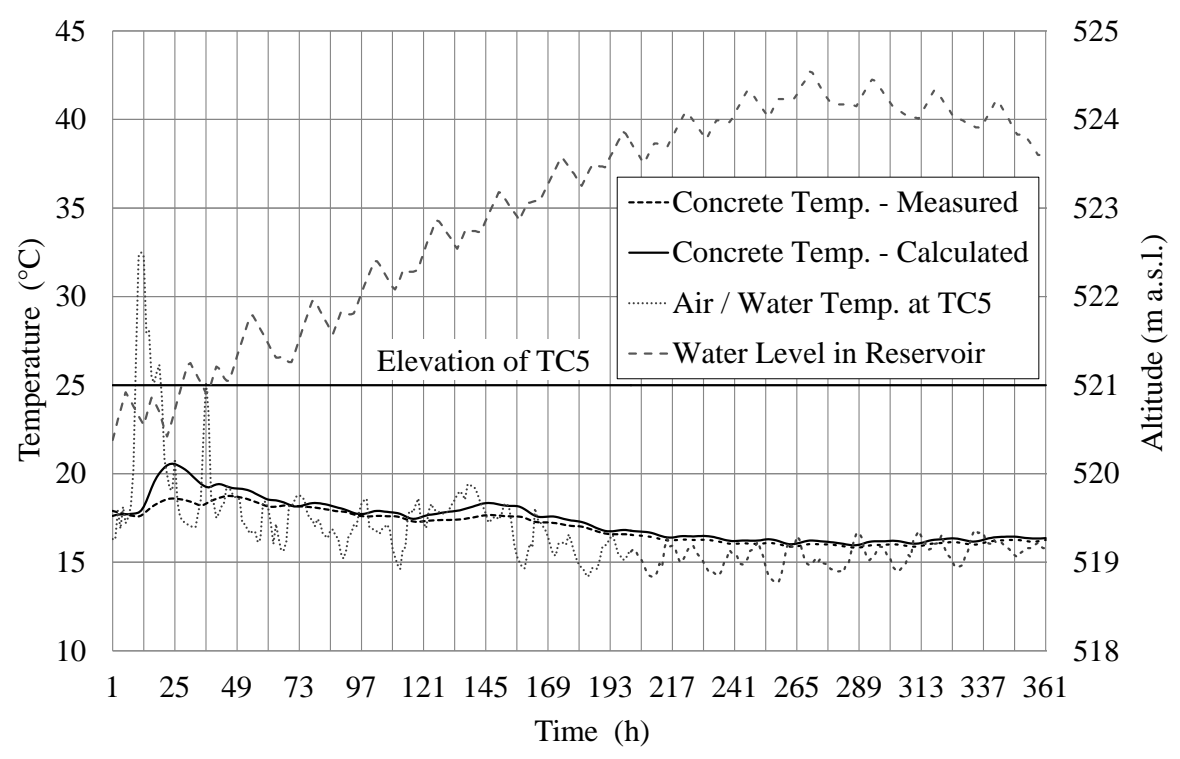

Fig. 12. Concrete temperatures at the gauge TC5 during the discussed period

\section{Conclusions}

This paper presented the results of heat transfer analysis in the case of a large concrete archgravity dam, which was investigated in detail. Following the recent installation of a sophisticated monitoring system, the concrete temperatures, the water temperatures and the temperatures of the surrounding conditions, i.e. the air temperatures, as well as the solar insolation, were continuously measured. Additionally, an equation related to nonlinear and non-stationary heat conduction for a two-dimensional space, for a homogeneous isotropic solid whose thermal conductivity is independent of the temperature, was solved numerically using the FEM. Appropriate boundary conditions were taken into account, considering the effects of the changing surrounding conditions (i.e. the convection and solar radiation considering the effect of shading), during the analysed period of 15 consecutive clear days during the summer. The results showed that the measured and calculated concrete temperatures at gauges TC1 to TC4, located in the upper borehole at distances of $0.1 \mathrm{~m}, 0.2 \mathrm{~m}, 0.5 \mathrm{~m}$ and $1.0 \mathrm{~m}$ from the downstream concrete surface, and at gauge TC5, located in the upstream borehole at a distance of $0.3 \mathrm{~m}$ from the upstream concrete surface, were in very good agreement.

\section{Acknowledgments}

This paper is part of research work that was performed within the scope of the first author's doctoral studies, and was partly funded by the European Union through the European Social Fund. 


\section{References}

Agullo, L., Mirambell, E., and Aguado, A. (1996). “A model for the analysis of concrete dams due to environmental thermal effects.” Int. J. Num. Meth. Heat Fluid Flow, 6(4), 25-36.

Ardito, R., Maier, G., and Massalongo, G. (2008). “Diagnostic analysis of concrete dams based on seasonal hydrostatic loading.” Eng. Struct., 30(11), 3176-3185.

Bernstone, C. (2006). “Automated performance monitoring of concrete dams.” Doctoral Thesis. Lund University, Sweden, 94 p.

Carslaw, H. S., and Jaeger, J. C. (1986). Conduction of heat in solids. Second Edition, Oxford University Press, New York.

Dilger, W. H., Ghali, A., Chan, M., Cheung, M. S., and Maes, M. A. (1983). "Temperature stresses in composite box girder bridges.” J. Struct. Eng., 109(6), 1460-1478.

Duffie, J. A., and Beckman, W. A. (2006). Solar engineering of thermal processes. Third edition, Wiley, New York, 908 p.

Ganelli, F., Beko, A., and Mordini, A. (2012). "Structural assessment of the Mignano solidgravity dam based on the monitoring data." Struct. Eng. Int., 22(1), 130-138.

Hu, Y., Zuo, Z., Li, Q., and Duan, Y. (2013). “Boolean-based surface procedure for the external heat transfer analysis of dams during construction." Mathematical Problems in Engineering, 2013, 1-17.

ICOLD (2000). Automated dam monitoring systems: Guidelines and case histories. Bulletin 118, 253 p.

ICOLD (2012). Dam surveillance guide. Bulletin 158, 109 p.

Ilc, A., Turk, G., Kavčič, F., and Trtnik, G. (2009). "New numerical procedure for the prediction of temperature development in early age concrete structures." Automation in Construction, 18(6), 849-855.

Ishikawa, M. (1991). “Thermal stress analysis of a concrete dam.” Computers \& Struct., 40(2), 347-352.

Jin, F., Chen, Z., Wang, J., and Yang, J. (2010). "Practical procedure for predicting non-uniform temperature on the exposed face of arch dams." Appl. Therm. Eng., 30(14-15), 2146-2156.

Labibzadeh, M., Sadrnejad, S. A., and Khajehdezfuly, A. (2010). "Thermal assessment of Karun1 dam." Trends in Applied Sciences Research, 5(4), 251-266.

Leger, P., Cote, M., and Tinawi, R. (1995). "Thermal protection of concrete dams subjected to freeze - thaw cycles.” Can. J. Civ. Eng., 22(3), 588-602.

Leger, P., and Leclerc, M. (2007). "Hydrostatic, temperature, time-displacement model for concrete dams.” J. Eng. Mech., 133(3), 267-277. 
Leger, P., and Seydou, S. (2009). "Seasonal thermal displacements of gravity dams located in northern regions.” J. Perform. Constr. Facil., 23(3), 166-174.

Leger, P., Venturelli, J., and Bhattacharjee, S. S. (1993a). "Seasonal temperature and stress distributions in concrete gravity dams. Part 1: modelling.” Can. J. Civil Eng., 20(6), 999-1017.

Leger, P., Venturelli, J., and Bhattacharjee, S. S. (1993b). "Seasonal temperature and stress distributions in concrete gravity dams. Part 2: behaviour.” Can. J. Civil Eng., 20(6), 1018-1029.

Maken, D., Leger, P., and Roth, S. (2014). "Seasonal thermal cracking of concrete dams in northern regions.” J. Perform. Constr. Facil., 28(4), 04014014.

Malkawi, A. I. H., Mutasher, S. A. and Qiu, T. J. (2003). “Thermal-structural modeling and temperature control of roller compacted concrete gravity dam.” J. Perform. Constr. Facil., 17(4), 177-187.

Malm, R., and Ansell, A. (2011). "Cracking of concrete buttress dam due to seasonal temperature variation.” ACI Struct. J., 108(1), 13-22.

MathWorks (2014). "MATLAB - The language of technical computing: numerical computing environment." <http://www.mathworks.com/products/matlab/> (Jul. 25, 2014).

Noorzaei, J., Bayagoob, K. H., Thanoon, W. A., and Jaafar, M. S. (2006). “Thermal and stress analysis of Kinta RCC dam.” Eng. Struct., 28(13), 1795-1802.

Obernhuber, P., and Perner, F. (2005). "Displacements in concrete dams caused by temperature variation.” Hydropower \& Dams, Issue 5, 80-86.

Saetta, A., Scotta, R., and Vitaliani, R. (1995). "Stress analysis of concrete structures subjected to variable thermal loads.” J. Struct. Eng., 121(3), 446-457.

Sheibany, F., and Ghaemian, M. (2006). "Effects of environmental action on thermal stress analysis of Karaj concrete arch dam.” J. Eng. Mech., 132(5), 532-544.

Toman, M. J. (1997). "Measurements of temperature and oxygen in the Moste reservoir." Report. University of Ljubljana - Biotechnical Faculty, Ljubljana (in Slovenian).

U.S. Army Corps of Engineers (1994). “Arch dam design.” Engineer Manual 1110-2-2201, Washington, D.C., USA, 120 p.

U.S. Army Corps of Engineers (1995). “Gravity dam design.” Engineer Manual 1110-2-2200, Washington, D.C., USA, 88 p.

Weber, B., Perner, F., and Obernhuber, P. (2010). "Displacements of concrete dams determined from recorded temperatures." Proc. 8th ICOLD European Club Symp., Innsbruck, Austria, 623628.

Wolfram Research Inc. (2014). "Mathematica 9: computational software program." $<$ http://www.wolfram.com/mathematica $>$ (Jul. 5, 2014). 
Wu, Y., and Luna, R. (2001). "Numerical implementation of temperature and creep in mass concrete." Finite Elements in Analysis and Design, 37(2), 97-106.

Xu, B. S., Liu, B. B., Zheng, D. J., Chen, L., Wu, C. C. (2012). “Analysis method of thermal dam deformation.” Sci China Tech Sci, 55(6), 1765-1772.

Yang, J., Hu, Y., Zuo, Z., Jin, F., and Li, Q. B. (2012). “Thermal analysis of mass concrete embedded with double-layer staggered heterogeneous cooling water pipes." Appl. Therm. Eng., 35(2012), 145-156.

Zhang, P. X., Ayari, M. L., and Robinson, L. C. (1997). "Role of fundamental heat transfer frequency in the computation of transient thermal fields in massive structures." Can. J. Civ. Eng., 24(6), 1059-1065.

Zienkiewicz, O. C. (1977). The finite element method. Third Edition (Expanded and Revised), McGraw-Hill Book Co., London, 787 p.

Žvanut, P., Vezočnik, R., Turk, G., and Ambrožič, T. (2014). "Determination of the shading of the downstream surface of the Moste concrete dam." Geodetski vestnik, 58(3), 453-465 (in Slovenian, abstract in English). 